\title{
Detection of Mechanical Deformation in Old Aged Power Transformer Using Cross Correlation Co-Efficient Analysis Method
}

\author{
Asif Islam $^{1}$, Shahidul Islam Khan ${ }^{2}$, Aminul Hoque ${ }^{2}$ \\ ${ }^{1}$ Energypac Engineering Ltd., Dhaka, Bangladesh \\ ${ }^{2}$ Department of Electrical \& Electronic Engineering, Bangladesh University of \\ Engineering \& Technology, Dhaka, Bangladesh \\ E-mail:asif038@gmail.com,shahidul@eee.buet.ac.bd,aminulhoque@eee.buet.ac.bd \\ Received May 25, 2011; revised June 28, 2011; accepted July 9, 2011
}

\begin{abstract}
Detection of minor faults in power transformer active part is essential because minor faults may develop and lead to major faults and finally irretrievable damages occur. Sweep Frequency Response Analysis (SFRA) is an effective low-voltage, off-line diagnostic tool used for finding out any possible winding displacement or mechanical deterioration inside the Transformer, due to large electromechanical forces occurring from the fault currents or due to Transformer transportation and relocation. In this method, the frequency response of a transformer is taken both at manufacturing industry and concern site. Then both the response is compared to predict the fault taken place in active part. But in old aged transformers, the primary reference response is unavailable. So Cross Correlation Co-Efficient (CCF) measurement technique can be a vital process for fault detection in these transformers. In this paper, theoretical background of SFRA technique has been elaborated and through several case studies, the effectiveness of CCF parameter for fault detection has been represented.
\end{abstract}

Keywords: Core Damage, Radial Deformation, Axial Deformation, Sweep Frequency Response Analysis, Cross Correlation Co-Efficient, Power Transformer

\section{Introduction}

Nowadays, reliability is an inevitable part of power system studies and operation, due to significant increase in the number of industrial electrical consumers. Power transformer is one of the major and critical elements in power system [1] in the area of reliability issue, since their outage may result in costly and time-consuming repair and replacement. Power transformers are specified to withstand the mechanical forces arising from both shipping and subsequent in-service events, such as faults and lightning. Once a transformer is damaged either heavily or slightly, the ability to withstand further incidents or short circuit test [2] becomes reduced. There is clearly a need to effectively identify such damage. A visual inspection is costly and does not always produce the desired results or conclusion [3-10]. During a field inspection, the oil has to be drained and confined space entry rules apply. Often, a complete tear down is required to identify the problem. An alternative method is to implement field-diagnostic techniques that are capable of detecting damage such as Frequency Response Analysis (FRA) [11-16].

FRA is a generally well-known testing technique within the industry to determine a transformer winding deformation, e.g. coils, turns, layers, HV leads, .etc, owning to short-circuit currents (faults), impact during transportation and aging [11]. Dick and Erven were the first to use the FRA method to detect the transformer winding deformation in 1978 [10]There are basically two techniques used for FRA measurements on power transformers; Low Voltage Impulse (LVI) based FRA and Sweep Frequency Response Analysis (SFRA) [16]. The two techniques are also termed FRA-I (impulse method) and FRA-S (swept-frequency method) [17]. The common strategy for both methods [18] is that the transformer impedance is measured at several different frequencies. The impedance will vary from one frequency to another due to the internal constitution of the transformer. 


\section{SFRA Theory}

When a transformer is subjected to FRA testing, the leads are configured in such a manner that four terminals are used. These four terminals can be divided into two unique pairs $[6,8,19]$, one pair for the input and the other pair for the output. These terminals can be modeled in a two-terminal pair or a two-port network configuration. Figure 1 illustrates a two-port network where $Z_{11}, Z_{22}$, $Z_{12}$ and $Z_{21}$ are the open-circuit impedance parameters.

The transfer function of this network [20] is represented in the frequency domain and is denoted by the Fourier variable $H(j \omega)$, where $(j \omega)$ denotes the presence of a frequency dependent function and $\omega=2 \pi f$. The Fourier relationship for the input/output transfer function is given by Equation (1).

$$
H(j \omega)=\frac{V_{\text {output }}(j \omega)}{V_{\text {input }}(j \omega)}
$$

when a transfer function is reduced to its simplest form, it generates a ratio of two polynomials. The main characteristics, such as half-power and resonance of a transfer function occur at the roots of the polynomials. The roots of the numerator are referred to as "zeros" and the roots of the denominator are "poles" [21]. Zeros produce an increase in gain while poles cause attenuation.

The goal of FRA is to measure the impedance model of the test specimen. When the transfer function $H(j \omega)$ is measured, it does not isolate the true specimen impedance $Z(j \omega)$. The true specimen impedance $Z(j \omega)$ is the RLC network which is positioned between the instrument leads and it does not include any impedance supplied by the test instrument. Figure 2 illustrates the RLC circuit with shunt resistor.

From the figure, Voltage division formula gives

$$
V_{2}(j \omega)=V_{1}(j \omega) \frac{R 1}{R 1+\frac{1}{\frac{1}{R 2}+\frac{1}{j \omega L}+j \omega C}}
$$

The transfer function is:

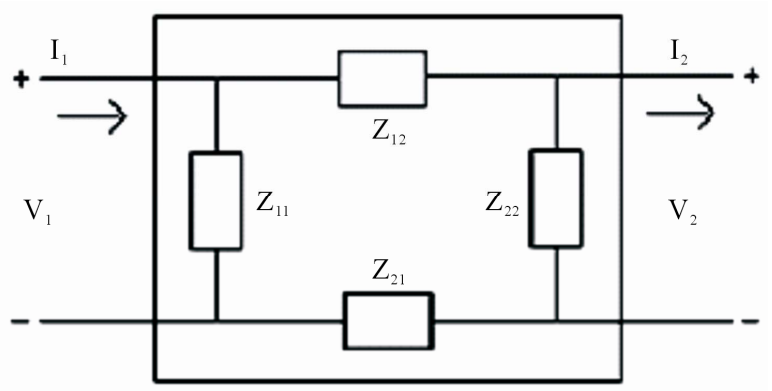

Figure 1. Two port network.

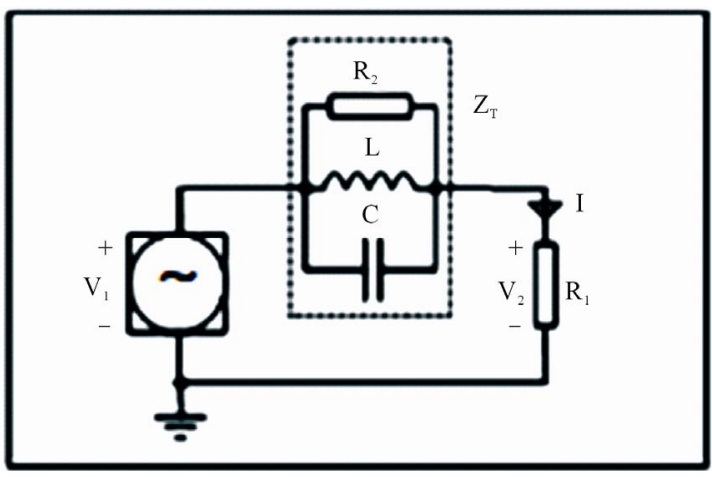

Figure 2. RLC circuit and shunt resistor.

$$
\begin{aligned}
H(j \omega) & =\frac{V_{2}(j \omega)}{V_{1}(j \omega)}=\frac{R_{1}}{R_{1}+\frac{1}{\frac{1}{R_{2}}+\frac{1}{j \omega L}+j \omega C}} \\
& =\frac{R_{1}\left(\frac{1}{R_{2}}+\frac{1}{j \omega L}+j \omega C\right)}{R_{1}\left(\frac{1}{R_{2}}+\frac{1}{j \omega L}+j \omega C\right)+1} \cdot \frac{j \omega L}{j \omega L} \\
& =\frac{R_{1}\left(j \omega \frac{L}{R_{2}}+1-\omega^{2} L C\right)}{R_{1}\left(j \omega \frac{L}{R_{2}}+1-\omega^{2} L C\right)+j \omega L}
\end{aligned}
$$

If $R_{2}$ would be removed from the circuit then the term $j \omega \frac{L}{R_{2}}$ disappears from the expressions above. It is now easy to see where the resonant frequency must occur:

$$
1-\omega_{r}^{2} L C=0=>\omega_{r}=\frac{1}{\sqrt{L C}}
$$

At resonant frequency the transfer function is

$$
\begin{aligned}
H(j \omega r) & =\frac{R_{1}\left(j \frac{L}{R_{2} \sqrt{L C}}+1-1\right)}{R_{1}\left(j \frac{L}{R_{2} \sqrt{L C}}+1-1\right)+j \frac{L}{\sqrt{L C}}} \\
& =\frac{\frac{R_{1}}{R_{2}}}{\frac{R_{1}}{R_{2}}+1}=\frac{R_{1}}{R_{1}+R_{2}}
\end{aligned}
$$

What is really measured over the shunt resistor $R_{l}$ is the current $I$. So, the transfer function describes the admittance: $Y=\frac{I}{V_{1}}$. The impedance is thus: $Z=\frac{V_{1}}{I}$

The impedance at resonance (including the shunt re- 
sistor) is $Z(\omega r)=\frac{R_{1}+R_{2}}{R_{1}}$

The preferred method of engineers is to use the Bode Diagram. The Bode Diagram plots the magnitude and phase as follows:

$$
\begin{aligned}
& A(d B)=20 \log _{10}(H(j \omega)) \\
& A(\theta)=\tan ^{-1}(H(j \omega))
\end{aligned}
$$

The Bode Diagram [22] takes advantage of the asymptotic symmetry by using a logarithmic scale for frequency. It is more advantageous to plot $H(\mathrm{~s})$ logarithmically over large frequency spans. The logarithmic plot helps to maintain consistent resolution. Plots ranging from $10 \mathrm{~Hz}$ to $10 \mathrm{MHz}$ can be displayed as a single plot if they are formatted logarithmically. Figure 3 shows a typical response for a high voltage star connected winding. The frequency range of interest is between $20 \mathrm{~Hz}$ and $2 \mathrm{MHz}$.

Experience has shown that different sub-bands are dominated [23] by different internal components of the transformer and are subsequently more sensitive to different types of failures, as summarized in Table 1. Measurements above $2 \mathrm{MHz}$ tend to be dominated by

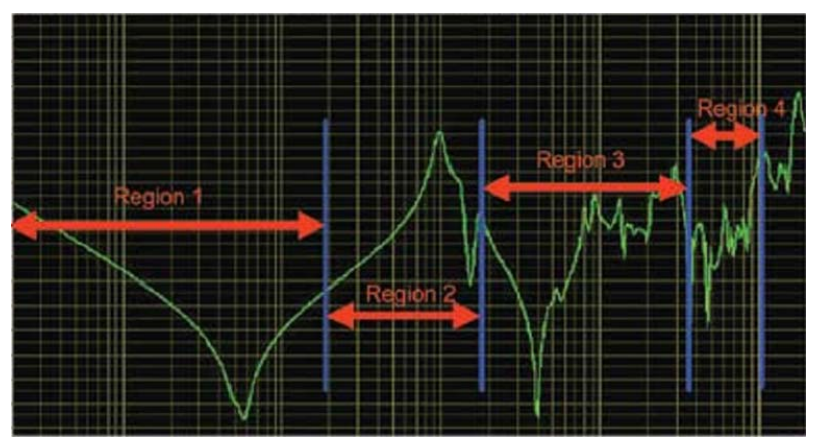

Figure 3. Frequency analysis bands.

Table 1. Frequency sub-band sensitivity.

\begin{tabular}{cccc}
\hline Region & $\begin{array}{c}\text { Frequency } \\
\text { Sub-Band }\end{array}$ & Component & Failure Sensitivity \\
\hline 1. & $<2 \mathrm{kHz}$ & $\begin{array}{c}\text { Main core bulk } \\
\text { and winding } \\
\text { inductance }\end{array}$ & $\begin{array}{c}\text { Core deformation, } \\
\text { open circuits, shorted } \\
\text { turns and residual } \\
\text { magnetism }\end{array}$ \\
2. $2 \mathrm{kHz}$ to $20 \mathrm{kHz}$ & $\begin{array}{c}\text { Bulk component } \\
\text { and shunt } \\
\text { impedances }\end{array}$ & $\begin{array}{c}\text { Bulk winding } \\
\text { movement between } \\
\text { windings and clamping } \\
\text { structure }\end{array}$ \\
3. & $20 \mathrm{kHz}$ to 400 & $\begin{array}{c}\text { Main windings } \\
\mathrm{kHz}\end{array}$ & $\begin{array}{c}\text { Deformation within the } \\
\text { main or top windings }\end{array}$ \\
4. & $400 \mathrm{kHz}$ to 1 & $\begin{array}{c}\text { Main windings, } \\
\text { top windings and } \\
\text { internal leads }\end{array}$ & $\begin{array}{c}\text { Movement of the main } \\
\text { impedance variations }\end{array}$ \\
\hline
\end{tabular}

variations in grounding practices for test leads.

\section{Measurement Procedure}

The FRAX "Generator" (Gen.) generates (Figure 4) a sinusoidal voltage at a selected frequency and measures the input voltages, amplitude and phase, on two input channels "Reference" (Ref.) and "Measure" (Meas.). The instrument stores "Amplitude" and "Phase" data for both "Reference" channel and "Measure" channel as well as the ratio "Measure" divided by "Reference". The values can be plotted and exported as Magnitude, Phase, Impedance, Impedance-Phase, Admittance and more. The "Custom models" function makes it possible to calculate almost any parameter based on the measured/stored data. FRAX uses the sine correlation technique [24]. This means that the input voltages are multiplied by a sine and a cosine, and then averaged over an integer multiple of the interval of time. The sine, cosine and the voltage applied have exactly the same frequency. The sine correlation technique is well known and is suitable for Sweep Frequency Response Analysis (SFRA) measurements. Since the signals on the two input channels are treated the same way, the phase resolution between these two channels is very high. The rejection of DC offset and harmonics - referred to as the applied voltage - are in theory infinite. By increasing the integration cycles, the rejection gradually improves.

The IF Bandwidth is commonly used as a parameter defining the bandwidth around the applied signal analyzed. An IF bandwidth of $10 \%$ of the active frequency is equivalent to 12 cycles of integration. When considering SFRA measurements, winding measurements realistically consist of three categories. The winding categories are high-voltage, low-voltage, inter winding. (Figures 5 -7)

Figure 8 presents a high-voltage winding trace, a low-voltage winding trace and an inter-winding trace together from a common test specimen. This illustrates their general relationship.

\section{Response Analysis}

For the analysis of a measured response, the response in

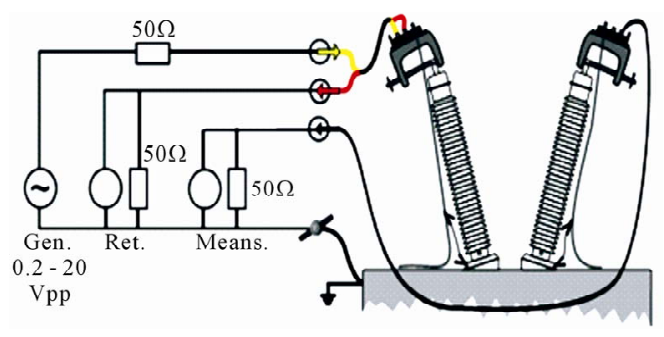

Figure 4. SFRA terminal connection. 


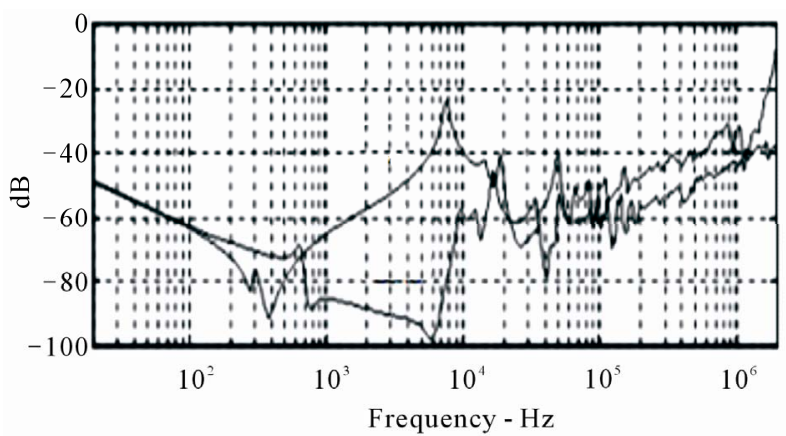

Figure 5. HV winding response.

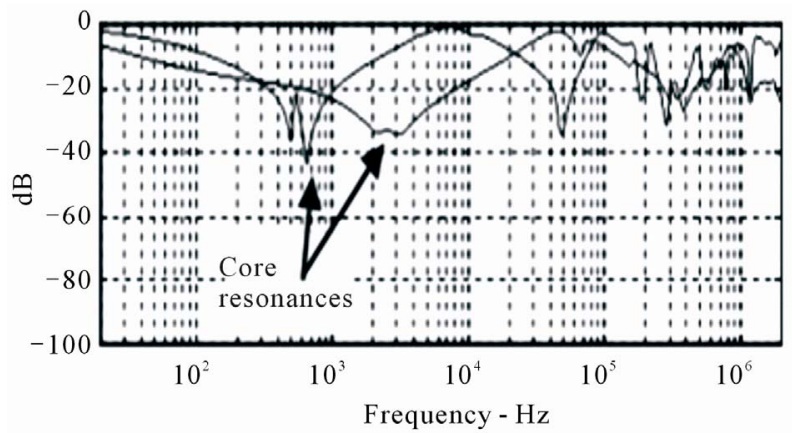

Figure 6. LV winding response.

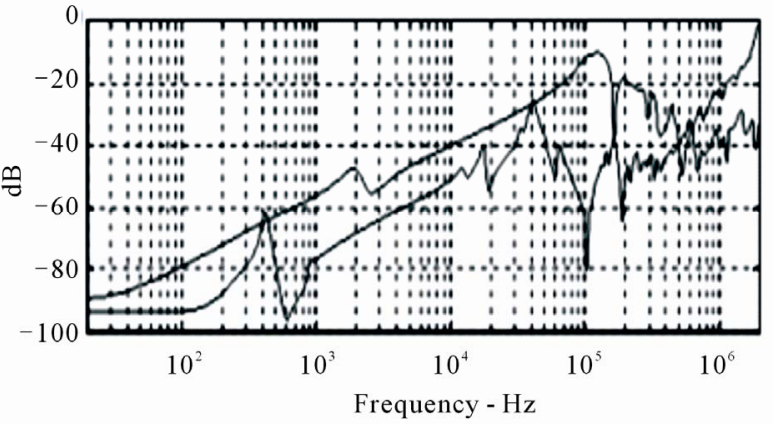

Figure 7. Inter winding response.

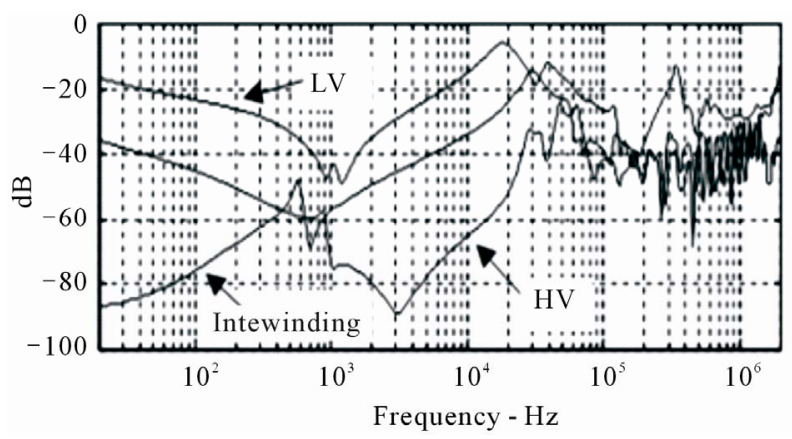

Figure 8. Complete response.

compared with one of the following:

- An earlier result [25] for the same phase tested with the same tap changer position.
- If no earlier result is available then another phase [23] of the same transformer, tested at the same occasion.

- The same phase, same tap changer position but on a unit believed to be of the same design group and made at the same factory.

It is found that Cross Correlation [20] coefficient (CCF) is the most reliable statistical indicator to extract information from comparison method. The CCF is defined as:

$$
\mathrm{CCF}=\frac{\sum_{i=1}^{n}\left(X_{i}-\bar{X}\right)\left(Y_{i}-\bar{Y}\right)}{\sqrt{\sum\left(X_{i}-\bar{X}\right)^{2} * \sum\left(Y_{i}-\bar{Y}\right)^{2}}}
$$

where $X_{i}$ and are $Y_{i}$ are the two series (or trace in the case of SFRA) being compared at each individual frequency ' $i$ ' and X-bar and Y-bar are the means. Equation (2) assumes two real series. In the case of signal processing the math becomes a little more involved, but the end results is still a coefficient between 1 and -1 . In SFRA analysis negative CCF are not common but they do occur on occasion. Regardless, negative correlation coefficients are not considered acceptable when trying to look for deviations between traces.

Normalizing the results to the individual power spectrums is what allows this resulting waveform to be expressed in a simple single coefficient. Table 2 helps provide a rough estimate of what the $\mathrm{CCF}$ means in simple language.

\section{Fault Diagnosis}

The following two case studies (Table 3) demonstrate two scenarios where SFRA response has been used to detect deformation or damage taken place in transformers.

Case 1: 41.67 MVA, 132/33 kV, 3 $\varphi$ Power Transformer at $132 \mathrm{kV}$ Substation

The results here are from a three phase 25/41.67 MVA,

Table 2. Outcome of CCFs value.

\begin{tabular}{cc}
\hline Decision & CCF \\
\hline Good match & $0.95-1.0$ \\
Close match & $0.90-0.94$ \\
Poor match & $\leq 0.89$ \\
No or very poor match & $\leq 0.0$ \\
\hline
\end{tabular}

Table 3. Case study of fault condition.

\begin{tabular}{ccccc}
\hline Case & $\begin{array}{c}\text { Capacity } \\
\text { MVA }\end{array}$ & $\begin{array}{c}\text { HT Voltage } \\
\mathrm{kV}\end{array}$ & $\begin{array}{c}\text { LT Voltage } \\
\mathrm{kV}\end{array}$ & Year of manufacture \\
\hline 1 & 41.67 & 132 & 33 & 1998 \\
2 & 14 & 33 & 11.6 & 1991 \\
\hline
\end{tabular}


132/33 kV (vector group Dyn-1) power transformer manufactured by EMCO Transformers Ltd. (Maharastra, India) at 1998 for Bangladesh Power Development Board (BPDB) $132 \mathrm{kV}$ sub-station. The transformer had tripped out of service on protection. No reference factory results were available for this unit. The phase-to-phase HV results didn't show typical variations from standard $\mathrm{HV}$ delta winding response. An overall look at the LV winding has showed several shifts between $200 \mathrm{kHz}$ and $2 \mathrm{MHz}$. This is shown in Figure 9 where it is clear that $\mathrm{H} 3-\mathrm{H} 0$ has consistently shifted at higher frequencies with respect to $\mathrm{H} 2-\mathrm{H} 0$ and $\mathrm{H} 1-\mathrm{H} 0$.

This is an indication of axial winding movement at X3 (Blue/C phase) phase. From CCF analysis method results (Table 4), this prediction can be more confirmed.

From the table, it is clearly visible that CCF values of phase A and phase B fulfill "Good Match" criteria in all 4 frequency sub-band regions. CCF values of phase $\mathrm{C}$ both with phase A or phase B meet up either "Good Match" or "Close Match" criteria in all bands except region 3. At region 3, both $\mathrm{CCF}$ values of phase $\mathrm{C}$ $(0.7263$ and 0.7681$)$ drops down vigorously at "Poor Match" level.

Removing the transformer top cover, the active part was brought out and after a through physical inspection, the prediction became true with damage of LV (phase C) coil (Figure 10).

Case 2: 14 MVA, 33/11.6 kV, 3 $\varphi$ Power Transformer at $33 \mathrm{kV}$ Substation

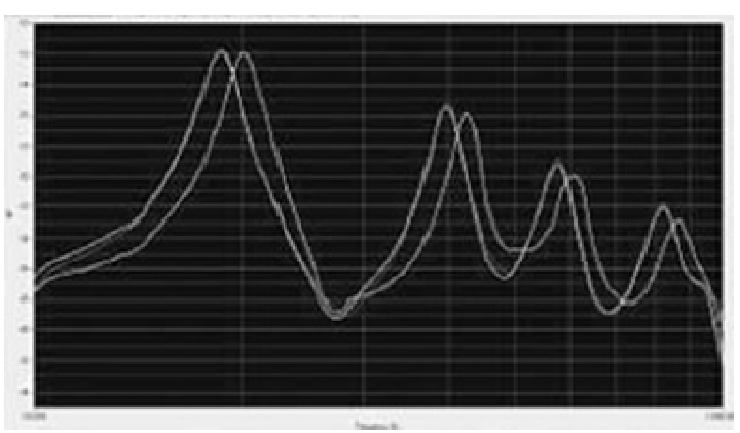

Figure 9. Close zoom of LV winding response $(100 \mathrm{kHz}-1$ MHz).

Table 4. Test result of $L V$ winding keeping $\mathrm{HV}$ open.

\begin{tabular}{cccc}
\hline \multirow{2}{*}{ Frequency Sub-band } & \multicolumn{3}{c}{ CCF results } \\
\cline { 2 - 4 } & $\begin{array}{c}\text { X1 - X0, } \\
\text { X2 - X0 }\end{array}$ & $\begin{array}{c}\text { X2 - X0, } \\
\text { X3 X }\end{array}$ & $\begin{array}{c}\text { X3 - X0 } \\
\text { X1 - X0 }\end{array}$ \\
\hline $0-2 \mathrm{kHz}$ & 0.9981 & 0.9925 & 0.9954 \\
$2 \mathrm{kHz}-20 \mathrm{kHz}$ & 0.9943 & 0.9868 & 0.9736 \\
$20 \mathrm{kHz}-400 \mathrm{kHz}$ & 0.9853 & 0.7263 & 0.7681 \\
$400 \mathrm{kHz}-1 \mathrm{MHz}$ & 0.9892 & 0.9475 & 0.9424 \\
\hline
\end{tabular}

The subjected transformer was running at Dhaka Power Distribution Company (DPDC). It is a 10/14 MVA, 33/11.6 kV (vector group - YNd11) power transformer manufactured by Brush Transformers Ltd. (Loughborough, England) at 1991. Due to its age of 20 years, frequency response of this transformer was taken to predict its aging effect. At first, test was carried on HV side keeping LV side open followed by LV side shorted. Corresponding Bode Plot response has been shown in Figures 11 and 12.

From the CCF result (Tables 5 and 6), it is easily viewable that the matching is very poor at low frequency region $(0-2 \mathrm{kHz})$. This may be due to core deformation

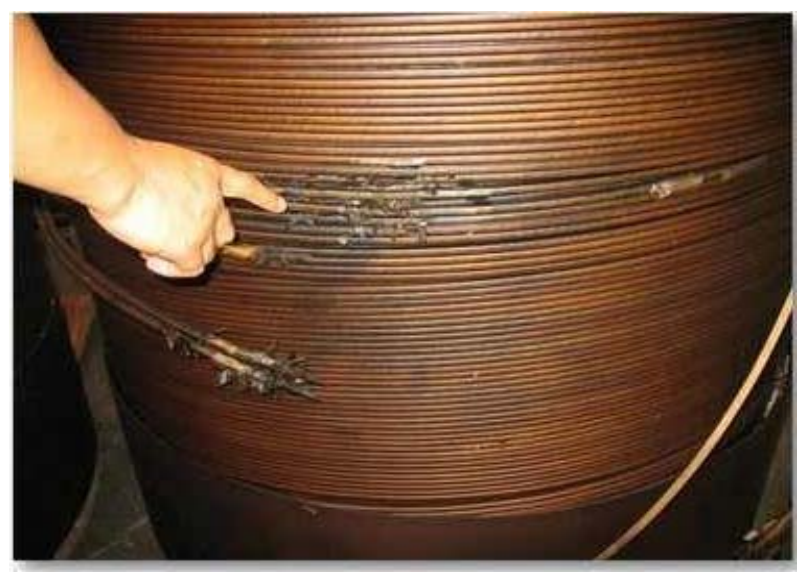

Figure 10. Damaged LV (phase-C) coil.

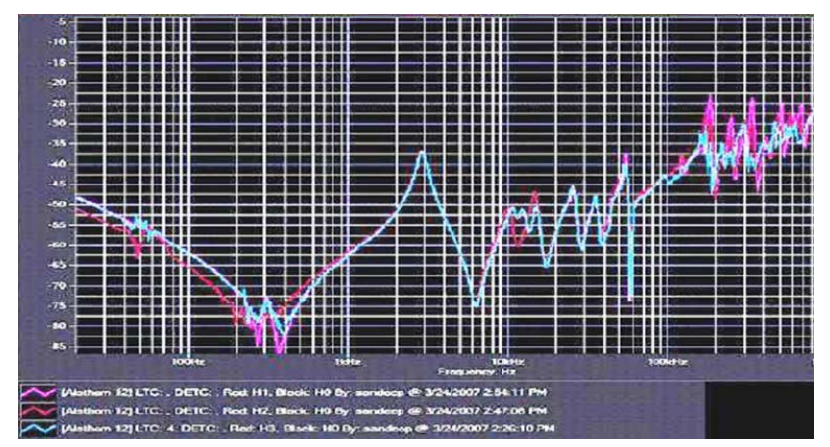

Figure 11. HV winding response (LV open).

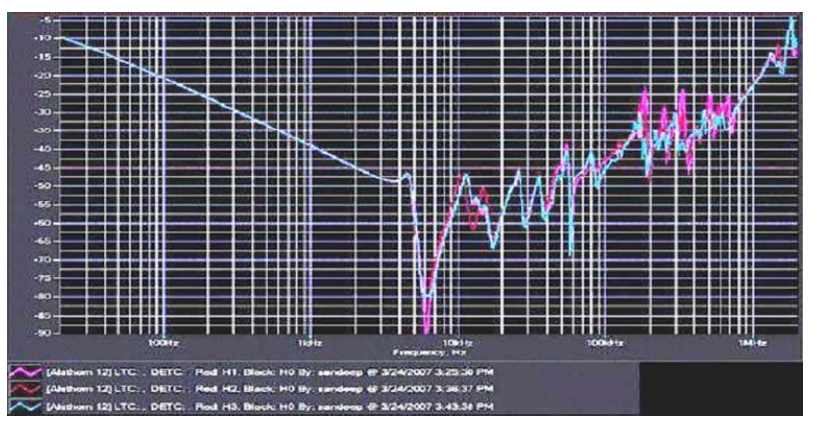

Figure 12. HV winding response (LV short). 
as a result of axial stress because the transformer is running for a long time (20 years). Again, poor matching at higher region $(400 \mathrm{kHz}-1 \mathrm{MHz})$ indicates main coil deformation either by radial stress or by axial stress. This deformation is more severe for A phase (Red phase).

From LV winding response (Figure 13) and corresponding CCF calculation (Table 7), the previous assumption becomes stronger. Poor matching at low frequency region $(0-2 \mathrm{kHz})$ and high frequency region $(400 \mathrm{kHz}-1 \mathrm{MHz})$ again spans the prediction of core damage and main winding movement firmly. After replacing the transformer from the system, it was dissected and both the prediction became true

\section{Conclusions}

Sweep frequency response analysis method has been applied to a number of three phase and single phase

Table 5. CCF of HV winding keeping LV open.

\begin{tabular}{cccc}
\hline \multirow{2}{*}{ Frequency Sub-band } & \multicolumn{3}{c}{ CCF results } \\
\cline { 2 - 4 } & $\begin{array}{c}\mathrm{X} 1-\mathrm{X} 0, \\
\mathrm{X} 2-\mathrm{X} 0\end{array}$ & $\begin{array}{c}\mathrm{X} 2-\mathrm{X} 0, \\
\mathrm{X} 3-\mathrm{X} 0\end{array}$ & $\begin{array}{c}\mathrm{X} 3-\mathrm{X} 0, \\
\text { X1 - X0 }\end{array}$ \\
\hline $0-2 \mathrm{kHz}$ & 0.7981 & 0.7825 & 0.9914 \\
$2 \mathrm{kHz}-20 \mathrm{kHz}$ & 0.9743 & 0.9841 & 0.9736 \\
$20 \mathrm{kHz}-400 \mathrm{kHz}$ & 0.9523 & 0.9267 & 0.9081 \\
$400 \mathrm{kHz}-1 \mathrm{MHz}$ & 0.8394 & 0.8975 & 0.8427 \\
\hline
\end{tabular}

Table 6. CCF of HV winding keeping LV short.

\begin{tabular}{cccc}
\hline \multirow{2}{*}{ Frequency Sub-band } & \multicolumn{3}{c}{ CCF results } \\
\cline { 2 - 4 } & $\begin{array}{c}\mathrm{X} 1-\mathrm{X} 0, \\
\mathrm{X} 2-\mathrm{X} 0\end{array}$ & $\mathrm{X} 2-\mathrm{X} 0$, & $\mathrm{X} 3-\mathrm{X} 0$ \\
$\mathrm{X} 1-\mathrm{X} 0$ \\
\hline $0-2 \mathrm{kHz}$ & 0.9981 & 0.9925 & 0.9954 \\
$2 \mathrm{kHz}-20 \mathrm{kHz}$ & 0.9743 & 0.9861 & 0.9786 \\
$20 \mathrm{kHz}-400 \mathrm{kHz}$ & 0.9354 & 0.9283 & 0.9217 \\
$400 \mathrm{kHz}-1 \mathrm{MHz}$ & 0.8113 & 0.8671 & 0.8039 \\
\hline
\end{tabular}

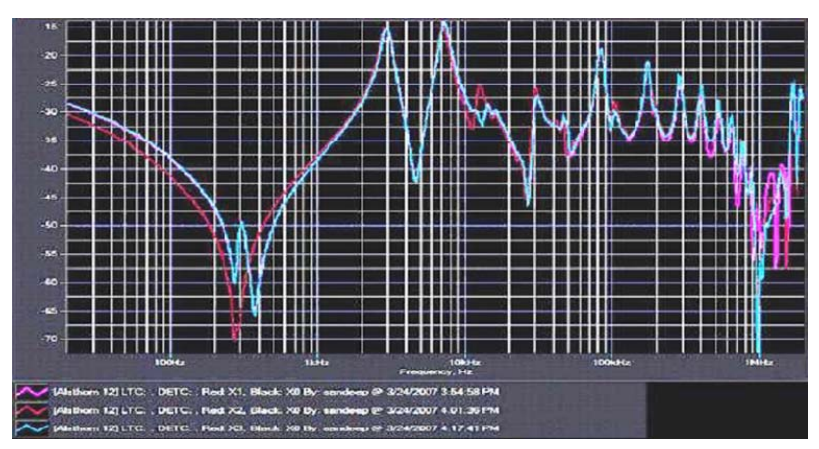

Figure 13. LV winding response (HV open).
Table 7. CCF of LV winding keeping HV open.

\begin{tabular}{cccc}
\hline \multirow{2}{*}{ Frequency Sub-band } & \multicolumn{3}{c}{ CCF results } \\
\cline { 2 - 4 } & $\begin{array}{c}\mathrm{X} 1-\mathrm{X} 0, \\
\mathrm{X} 2-\mathrm{X} 0\end{array}$ & $\begin{array}{c}\mathrm{X} 2-\mathrm{X} 0, \\
\mathrm{X} 3-\mathrm{X} 0\end{array}$ & $\begin{array}{c}\mathrm{X} 3-\mathrm{X} 0, \\
\mathrm{X} 1-\mathrm{X} 0\end{array}$ \\
\hline $0-2 \mathrm{kHz}$ & 0.8381 & 0.8325 & 0.9907 \\
$2 \mathrm{kHz}-20 \mathrm{kHz}$ & 0.9943 & 0.9921 & 0.9936 \\
$20 \mathrm{kHz}-400 \mathrm{kHz}$ & 0.9825 & 0.9867 & 0.9781 \\
$400 \mathrm{kHz}-1 \mathrm{MHz}$ & 0.8493 & 0.9275 & 0.8027 \\
\hline
\end{tabular}

power transformers of different vector groups. This method is also applicable for mechanical deformation and damage diagnosis in distribution transformers. The parameter Cross Correlation Co-efficient (CCF) is found to vary significantly and consistently with mechanical displacements taken place in transformers. So it can be considered as the most effective indicator to predict the internal physical condition of the active part of a transformer.

\section{Acknowledgements}

The authors would like to acknowledge the contributions made by Mr. Rashiduzzaman Bulbul, Assistant Engineer (Testing, Transformer), Energypac Engineering Ltd. for his logistic and data support. They are also grateful to Energypac Engineering Ltd. for frequent high voltage instruments using facility.

\section{References}

[1] T. McGrail, "Transformer Frequency Response Analysis: An Introduction," The International Electrical Testing Association, 1 April 2005.

[2] M. Darveniza, D. J. T. Hill, T. T. Le and T. K. Saha, "Investigations into Effective Methods for Assessing the Condition of Insulation in Aged Power transformers," IEEE Transactions on Power Delivery, Vol. 13, No. 4, 1998, pp. 1214-1223. doi:10.1109/61.714487

[3] A. Kuechler, F. Huellmandel, K. Boehm, C. Neumann, N. Koch, K. Loppach, C. Krause and J. J. Alff, "Condition Assessment of Aged Transformer Bushing Insulations," Water and Energy Abstracts, Vol. 19, No. 4, 2006, pp. $1-10$.

[4] M. De Nigris et al., "Application of Modern Techniques for the Condition Assessment of Power Transformers," Cigré Session 2004, Paper No. A2-207.

[5] B. Richardson, "Diagnostics and Condition Monitoring of Power Transformers," IEEE ABB Power Transformer Research and Development Ltd., 1997.

[6] A. P. Purnomoadi and D. Fransisco, "Modeling and Diagnostic Transformer Condition Using Sweep Frequency Response Analysis," Proceeding of ICPADM 9th Inter- 
national Conference on the Properties and Applications of Dielectric Materials, Harbin, 19-23 July 2009, pp. 1059-1063.

[7] P. Werelius, M. Ohlen, L. Adeen, E. Brynjebo, et al., "Measurement Considerations Using SFRA for condition Assessment of Power Transformers," Proceeding of CMD International Conference on Condition Monitoring and Diagnosis, Beijing, 21-24 April 2008, pp. 898-901.

[8] G. Joginadham, H. A. Mangalvedekar and A. Venkatasami, "Development of Networks for SFRA Data Using Circuit Synthesis," Proceeding of CMD International Conference on Condition Monitoring and Diagnosis, Beijing, 21-24 April 2008, pp. 1350-1353. doi:10.1109/CMD.2008.4580519

[9] S. Patil and A. Venkatasami "Realization of Transformer Winding Network from Sweep Frequency Response Data," Proceeding of CMD International Conference on Condition Monitoring and Diagnosis, Beijing, 21-24 April 2008, pp. 505-508. doi:10.1109/CMD.2008.4580336

[10] E. Al-Ammar, G. G. Karady and O. P. Hevia, "Improved Technique for Fault Detection Sensitivity in Transformer Maintenance Test," 2007 IEEE Power Engineering Society General Meeting, Tampa, 24-28 June 2007, pp. 505508.

[11] S. Ryder, "Diagnosing Transformer Faults Using Frequency Response Analysis: Results from Fault Simulations," IEEE/ PES Summer Meeting, Chicago, 2002, pp. 399-404.

[12] S. M. Islam, "Detection of Shorted Turns and Winding Movements in Large Power Transformers Using Frequency Response Analysis," IEEE Power Society Winter Meeting, Singapore, Vol. 3, 2000, pp. 2233-2238.

[13] J. A. Lapworth and T. J. Noonan, "Mechanical Condition Assessment of Power Transformers Using Frequency Response Analysis," Proceedings of the 1995 International Client Conference, Boston, 22-26 May 1995.

[14] L. Coffeen, J. Britton and J. Rickmann, "A New Technique to Detect Winding Displacements in Power Transformers Using Frequency Response Analysis," IEEE Power Technical Conference, Bologna, 23-26 June 2003, pp. 23-26. doi:10.1109/PTC.2003.1304329

[15] L. Moodley and B. de Klerk "Sweep Frequency Response Analysis as A Diagnostic tool to Detect Transformer Mechanical Integrity," eThekwini Electricity, Durban, 1978, pp. 1-9.
[16] S. Tenbohlen and S. A. Ryder, "Making Frequency Response Analysis Measurements: A Comparison of the Swept Frequency and Low Voltage Impulse Methods," XIIIth International Symposium on High Voltage Engineering, Delft, 25-29 August 2003.

[17] M. Wang, A. J. Vandermaar and K. D. Srivastava, "Transformer Winding Movement Monitoring in Service-Key Factors Affecting FRA Measurements," IEEE Electrical Insulation Magazine, Vol. 20, No. 5, 2004, pp 5-12. doi:10.1109/MEI.2004.1342427

[18] S. Tenbohlen and S. A. Ryder, "Making Frequency Response Analysis Measurements, a Comparison of the Swept Frequency and LV Impulse Methods," 13th International Symposium on HV Engineering, Delft University of Technology, Delft, 25-29 August 2003.

[19] J. Bak-Jensen, B. Bak-Jensen, and S. D. Mikkelsen, "Detection of Faults and Aging Phenomena in Transformers by Transfer Functions," IEEE Transactions on Power Delivery, Vol. 10, No. 1, 1999, pp. 308-314. doi:10.1109/61.368384

[20] Z. J. Jin, J. T. Li and Z. S. Zhu, "Diagnosis of Transformer Winding Deformation on the Basis of Artificial Neural Network," Proceedings of the 6th International Conference on Properties and Applications of Dielectric Materials, Xi'an Jiaotong University, Xi'an, 21-26 June 2000.

[21] T. K. Saha, A. Prasad and Z. T. Yao, "Voltage Response Measurements for the Diagnosis of Insulation Condition in Power Transformer," International Symposium on High Voltage Engineering, Bangalore, 19-25 August 2001.

[22] R. C. Dorf and R. H. Bishop, "Modern Control Systems," 10th Edition, Dorling Kindersley, New Delhi, 2005, p. 869.

[23] N. D. Cogger and R. V. Webb, "Frequency Response Analysis," Solartron Analytical, Technical Report 10, 1997.

[24] T. K. Saha and P. Purkait, "An Attempt to Correlate Time \& Frequency Domain Polarisation Measurements for the Insulation Diagnosis of Power Transformer," Proceedings of the IEEE Power Engineering Society General Meeting, Denver, 6-10 June 2004.

[25] S. Ryder, "Methods for Comparing Frequency Response Analysis Measurements," Conference Record of the 2002 IEEE International Symposium on Electrical Insulation, Boston, 7-10 April 2002, pp. 187-190. 